\title{
Fluorescent Silica Particles for Monitoring Oxygen Levels in Three-Dimensional Heterogeneous Cellular Structures
}

\author{
Miguel A. Acosta, Melissa Velasquez, Katelyn Williams, Julia M. Ross, and Jennie B. Leach \\ Department of Chemical, Biochemical \& Environmental Engineering, University of Maryland \\ Baltimore County, 1000 Hilltop Circle, ECS 314, Baltimore, Maryland 21250
}

\begin{abstract}
Bacterial biofilms are a major obstacle challenging the development of more effective therapies to treat implant infections. Oxygen availability to bacterial cells has been implicated in biofilm formation and planktonic cell detachment; however, there are insufficient tools available to measure oxygen concentrations within complex three-dimensional structures with $\sim 1 \mu \mathrm{m}$ resolution. Such measurements may complement measures of biofilm structure and cell activity to provide a more comprehensive understanding of biofilm biology. Thus, we developed oxygensensing microparticles specifically designed to characterize oxygen transport through the volume of bacterial biofilms. The Stöber method was used to synthesize monodisperse silica microparticles of approximately the same size as a bacterium $(\sim 1 \mu \mathrm{m})$. Two fluorophores, oxygensensitive $\mathrm{Ru}\left(\mathrm{Ph}_{2} \mathrm{phen}_{3}\right) \mathrm{Cl}_{2}$, and the reference fluorophore Nile blue chloride were immobilized on the surface of the particles. We demonstrate application of the microparticles toward measuring the oxygen concentration profiles within a live Staphylococcus aureus biofilm.
\end{abstract}

\section{Keywords}

Staphylococcus aureus; biofilms; Stöber synthesis; microparticles; oxygen sensors

\section{Introduction}

Staphylococcus aureus is a bacterial pathogen that has been associated with hospitalacquired infections, such as those related to prosthetic device implantations (Chu et al., 2005). These infections have proven difficult to treat due to $S$. aureus' ability to form organized biofilms (Gotz, 2002), which contribute to antibiotic resistance (Folkesson et al., 2008; Stewart and Costerton, 2001) and secondary metastatic infection caused by free flowing planktonic cells that detach from the biofilm (Lesens et al., 2004). Whereas the effects of soluble factors on planktonic cell adhesion and biofilm formation have been studied (Cramton et al., 2001), much is yet unknown about the processes that are unique to the biofilm interior, such as oxygen transport dynamics, that may contribute to antibiotic resistance and formation of secondary infections. This is due to the lack of adequate tools to map oxygen dynamics through complex three-dimensional cellular structures with a resolution on the order of a single bacterium $(\sim 1 \mu \mathrm{m})$.

Optical oxygen sensors based on fluorescence quenching have shown great potential to quantitatively map oxygen concentration in cell culture studies. Various sensors of this type have been developed using a wide variety of formats, such as patches (Ge et al., 2006), 
sensor films (John et al., 2003), fiber optics (Klimant et al., 1995; Wolfbeis, 2006), and nanoprobes (Brasuel et al., 2002; Lebedev et al., 2009). Recently, we reported fluorescent oxygen-sensing particles $(10-50 \mu \mathrm{m})$ which can be suspended within any transparent biomaterial and utilized to measure temporal and spatial changes in oxygen concentration through the volume of a biomaterial (Acosta et al., 2009). Herein, we report an adaptation of this technology suitable to measure oxygen profiles within bacterial biofilms. The particles were synthesized using an adaptation of the Stöber method for hydrolysis of tetraethylorthosilicate (TEOS) (Stöber et al., 1968) that yielded particles roughly the size of $S$. aureus cells $(\sim 1 \mu \mathrm{m})$. Use of the Stöber synthesis has been reported previously for other optical sensing applications, such as for the detection of nitro compounds like trinitrotoluene (TNT) (Gao et al., 2008). The protocol consisted of synthesizing the microparticles and then immobilizing the oxygen-sensitive fluorophore tris (4,7-diphenyl-1,10-phenanthroline) ruthenium (II) dichloride, or $\mathrm{Ru}\left(\mathrm{Ph}_{2} \mathrm{phen}_{3}\right) \mathrm{Cl}_{2}$, and the oxygen-insensitive fluorophore Nile blue chloride, to serve as a reference for ratiometric measurements, to their surface. We present characterization of these microparticles and demonstrate that the particles can be suspended within the volume of a live $S$. aureus biofilm. Oxygen levels were measured within the biofilm and compared to biofilm structure.

\section{Materials and Methods}

All reagents were purchased from Fisher Scientific (Pittsburgh, PA) or Sigma-Aldrich (St. Louis, MO) unless otherwise noted.

\section{Synthesis of Fluorescent Silica Microparticles}

The oxygen-sensing particles were synthesized by adapting the Stöber method (Stöber et al., 1968) to allow for immobilization of fluorophores onto silica particles. First, three solutions were prepared. Solution 1 consisted of $4 \mathrm{~mL}$ of $30 \%$ ammonium hydroxide, $3.5 \mathrm{~mL}$ of water, and $17.5 \mathrm{~mL}$ of a 1:3 (v/v) methanol-propanol solution. Solution 2 consisted of $4 \mathrm{~mL}$ of the 1:3 methanol-propanol and $1 \mathrm{~mL}$ of TEOS. Finally, solution 3 consisted of $32 \mathrm{~mL}$ of the 1:3 methanol-propanol and $8 \mathrm{~mL}$ of TEOS. Solutions 1 and 2 were combined in a roundbottomed flask suspended in a water bath at room temperature and magnetically stirred for $15 \mathrm{~min}$. Then solution 3 was added drop-wise at a rate of 1 drop every 3-5 s. After solution 3 was dispensed completely, the solutions were allowed to react with stirring for $6 \mathrm{~h}$. The resulting suspension was centrifuged at $1,900 \times g$ for $10 \mathrm{~min}$ and the particles were then washed by re-suspension in deionized water. This washing procedure was carried out seven times with deionized water and once with ethanol. The particles were then dried overnight at $70^{\circ} \mathrm{C}$.

Next, the oxygen-sensitive fluorophore tris (4,7-diphenyl-1,10-phenanthroline) ruthenium (II) dichloride, or $\mathrm{Ru}\left(\mathrm{Ph}_{2} \mathrm{phen}_{3}\right) \mathrm{Cl}_{2}$, and the oxygen-insensitive fluorophore Nile blue chloride were immobilized onto the dry particles. A suspension of $2 \mathrm{~g}$ of the silica particles and $40 \mathrm{~mL}$ of $0.01 \mathrm{~N} \mathrm{NaOH}$ was sonicated for $10 \mathrm{~min}$ to break particle clumps, and then magnetically stirred for $30 \mathrm{~min}$. Next, $10 \mathrm{~mL}$ of a $0.5 \mathrm{mM}$ solution of $\mathrm{Ru}\left(\mathrm{Ph}_{2} \mathrm{phen}_{3}\right) \mathrm{Cl}_{2}$ (GFS Chemicals, Powell, OH) in ethanol, and $10 \mathrm{~mL}$ of a $0.5 \mathrm{mM}$ solution of Nile blue chloride in ethanol, were added simultaneously and then stirred for another $30 \mathrm{~min}$. The particles were then washed, as described above, three times with deionized water (or until the supernatant was observed to be clear) and once with ethanol, dried overnight at $70^{\circ} \mathrm{C}$, and stored in the dark.

Microparticle size distribution was measured using a Multisizer 3 Coulter Counter (Beckman-Coulter, Fullerton, CA). Additionally, the microparticles were imaged using a JEOL JSM-5600 Scanning Electron Microscope (JEOL, Tokyo, Japan) to assess their 
morphology. Gold-palladium sputter coating on the microparticles was performed with a Denton Vacuum Desk II (Denton Vacuum, Moorestown, NJ) at 45 A for $60 \mathrm{~s}$.

\section{Parallel-Plate Flow Chamber System}

Microparticle calibration and biofilm experiments were carried out in a parallel-plate flow chamber. The flow chamber consisted of three sections that were held together by vacuum: (1) a polycarbonate block to form the top of the flow area, (2) a silicone gasket (McMasterCarr; $38 \mathrm{~mm} \times 14 \mathrm{~mm}$ in length and width, respectively), which determined the total height of the flow area, and (3) a glass slide that served as the bottom of the flow chamber and held the sample of interest. Two silicone gaskets were utilized, a 1-mm thick gasket for microparticle calibration and a $600-\mu \mathrm{m}$ thick gasket for biofilm experiments. Flow chamber's flow area has a depression of $400 \mu \mathrm{m}$. Thus, with the placement of the silicone gasket, flow area height was calculated at $600 \mu \mathrm{m}$ for microparticle calibration and $200 \mu \mathrm{m}$ for biofilm experiments.

For microparticle calibration, the flow chamber was mounted on the stage of the fluorescence microscope and was connected in a closed-loop with a 500-mL water reservoir and a peristaltic pump via 1.6-mm ID/4.8-mm OD Tygon tubing (Cole-Parmer, Vernon Hills, IL). Water flow through flow chamber system was set at $5 \mathrm{~mL} / \mathrm{min}$. The water reservoir housed a traditional dissolved oxygen meter (VWR, West Chester, PA) and was also connected to two rotameters (Cole-Parmer) that were used to control incoming gas flow from nitrogen and air tanks to the reservoir.

For the biofilm experiments, the flow chamber was connected to a syringe pump (Harvard Apparatus, Holliston, MA) and to a 500-mL empty reservoir for waste capture. Infusion of bacteria suspension, media, staining, and washing solutions was set to $0.56 \mathrm{~mL} / \mathrm{min}$, which corresponded to a shear rate of $100 \mathrm{~s}^{-1}$, as estimated by the following equation for a section of rectangular area (Busscher and van der Mei, 2006):

$$
Q=\frac{w h^{2} \dot{\gamma}}{6}
$$

where $Q$ is the volumetric flow rate, $w$ the flow area width, $h$ the height of the flow area, and $\dot{\gamma}$ is the shear rate. The $100 \mathrm{~s}^{-1}$ falls within the reported values for the range of shear rates in human blood vessels, for example, in veins where the shear rate range have been reported to be $20-100 \mathrm{~s}^{-1}$ (Goldsmith and Turitto, 1986).

\section{Microparticle Calibration}

Microparticle fluorescence intensity data as a function of dissolved oxygen content was obtained in the flow chamber and analyzed according to published methods (Acosta et al., 2009). Briefly, nitrogen and air were combined and sparged into a water reservoir to achieve step-wise increments in dissolved oxygen concentration. The water reservoir was connected to the flow chamber via a flow loop. Measurements from the dissolved oxygen meter and fluorescence images of the sensing microparticles were recorded every $30 \mathrm{~s}$. Each image was captured using a QDOT-605 filter set (Olympus, Center Valley, PA) for $\mathrm{Ru}\left(\mathrm{Ph}_{2} \mathrm{phen}_{3}\right) \mathrm{Cl}_{2}$ and a Cy5 filter set (Olympus) for Nile blue chloride. Excitation and emission wavelengths for $\mathrm{Ru}\left(\mathrm{Ph}_{2} \mathrm{phen}_{3}\right) \mathrm{Cl}_{2}$ are 470 and $610 \mathrm{~nm}$, respectively, and Nile blue chloride are 636 and $656 \mathrm{~nm}$, respectively. The selected exposure time for both $\mathrm{Ru}\left(\mathrm{Ph}_{2} \mathrm{phen}_{3}\right) \mathrm{Cl}_{2}$ and Nile blue chloride was $100 \mathrm{~ms}$. Images were captured at 10x magnification.

Image analysis was conducted using NIH Image-J freeware. Mean values of microparticle fluorescence intensity across the surface of the hydrogel were obtained by using a series of 
line profiles to segment each image across their width (at 10× magnification, image area was $887.52 \mu \mathrm{m} \times 660.48 \mu \mathrm{m})$. Images displaying $\mathrm{Ru}\left(\mathrm{Ph}_{2} \mathrm{phen}_{3}\right) \mathrm{Cl}_{2}$ and Nile blue chloride fluorescence were analyzed separately, excluding non-fluorescent microparticles from the analysis.

To correlate microparticle fluorescence to dissolved oxygen content, the two-site SternVolmer model was adapted to describe the relationship between fluorescence intensity of the $\mathrm{Ru}\left(\mathrm{Ph}_{2} \mathrm{phen}_{3}\right) \mathrm{Cl}_{2}$ fluorophore and oxygen concentration and normalize its fluorescence intensity to that of the Nile blue chloride reference fluorophore:

$$
\frac{I_{\mathrm{R}, 0}}{I_{\mathrm{R}}}=\left(\frac{f_{1}}{1+K_{\mathrm{SV}, 1}\left[\mathrm{O}_{2}\right]}+\frac{f_{2}}{1+K_{\mathrm{SV}, 2}\left[\mathrm{O}_{2}\right]}\right)^{-1}
$$

where $I_{R, 0}$ and $I_{\mathrm{R}}$ are the ratios of the fluorescence intensity of $\mathrm{Ru}\left(\mathrm{Ph}_{2} \mathrm{phen}_{3}\right) \mathrm{Cl}_{2}$ and Nile blue chloride in the absence and presence of oxygen, respectively, and $\left[\mathrm{O}_{2}\right]$ is the oxygen concentration. Carraway et al. (1991) demonstrated that for fluorescent organic-metal complexes immobilized on a polar carrier, such as $\mathrm{Ru}\left(\mathrm{Ph}_{2} \mathrm{phen}_{3}\right) \mathrm{Cl}_{2}$ immobilized on silica, a two-site Stern-Volmer model is better suited for calibration. The two-site Stern-Volmer model states that the $\mathrm{Ru}\left(\mathrm{Ph}_{2} \mathrm{phen}_{3}\right) \mathrm{Cl}_{2}$ fluorophore is divided into two populations through the volume of the carrier matrix, a "quenched" population and an "unquenched" population, with fractions $f_{1}$ and $f_{2}$ and their own Stern-Volmer quenching constants $K_{\mathrm{SV}, 1}$ and $K_{\mathrm{SV}, 2}$, respectively. Two assumptions were applied to Equation (2) for simplification: (1) $f_{2}=1-$ $f_{1}$ and (2) the quenching constant for the unquenched $\left(K_{\mathrm{SV}, 2}\right)$ populations was very small and thus assumed to be negligible. Then, Equation (2) was rearranged to have the form:

$$
\frac{I_{\mathrm{R}, 0}-I_{\mathrm{R}}}{I_{\mathrm{R}, 0}\left(f_{1}-1\right)+I_{\mathrm{R}}}=K_{\mathrm{SV}}\left[\mathrm{O}_{2}\right]
$$

where $f_{1}$ is the fraction of quenched fluorophore and $K_{\mathrm{SV}}$ is the Stern-Volmer quenching constant.

\section{Preparation of Collagen-Coated Cover Slips}

Collagen-coated cover slips were prepared by adaptation of previously published methods (Mascari and Ross, 2001; Mohamed et al., 2000, 1999). A $2 \mathrm{mg} / \mathrm{mL}$ solution of type I rat tail collagen (BD Biosciences, Bedford, MA) in 10 vol\% acetic acid was prepared. Fluorescent microparticles were added to this solution to a concentration of $1 \mathrm{mg} / \mathrm{mL}$. The solution was vortexed vigorously and sonicated for $5 \mathrm{~min}$ to break particle clumps. One hundred microliters of the collagen/microparticle suspension were dispensed onto a clean cover slip fitted with a silicone gasket cut to the flow chamber's dimensions. The solution was spread to cover the entire area of the mold, and allowed to adhere at room temperature for $1 \mathrm{~h}$. Then, excess collagen was rinsed off with deionized water. The cover slip was then coated with PBS until use.

\section{S. aureus Biofilm Culture and Staining}

The Phillips strain of $S$. aureus was first isolated from a patient with osteomyelitis (Patti et al., 1994) and was selected for these studies because it forms biofilms and has high affinity to collagen substrates. Tryptic soy broth (TSB; Difco, Detroit, MI) was used as growth medium for the bacteria cultures. For primary cultures, $10 \mu \mathrm{L}$ of $S$. aureus cells, collected from stocks stored at $-80^{\circ} \mathrm{C}$, were placed and cultured for $19 \mathrm{~h}$ in a conical flask with $50 \mathrm{~mL}$ of TSB at $37^{\circ} \mathrm{C}$ under constant agitation. 
Biofilms were grown by methods adapted from (Ymele-Leki and Ross, 2007) wherein $S$. aureus biofilms were reported after $6 \mathrm{~h}$ of growth under similar conditions. Primary cells were diluted to a ratio of $1: 40$ in $0.2 \% \mathrm{w} / \mathrm{v}$ sodium azide $\left(\mathrm{NaN}_{3}\right)$ in PBS with $0.2 \% \mathrm{w} / \mathrm{v}$ BSA and infused through the flow chamber for $6 \mathrm{~min}$. Unattached bacterial cells were washed by infusing PBS containing fluorescent microparticles at a concentration of $0.5 \mathrm{mg} / \mathrm{mL}$ for 10 min. This washing step also removed the sodium azide added to the bacterial cell suspension. Then TSB was infused for $6 \mathrm{~h}$ to allow biofilm growth and then the TSB was removed by infusing PBS containing fluorescent microparticles as described above. The washing steps included additional microparticles at different stages of biofilm development to place microparticles through the volume of the biofilm. All steps were carried out at $37^{\circ} \mathrm{C}$.

For labeling the $S$. aureus cells, $\mathrm{F}\left(\mathrm{ab}^{\prime}\right)_{2}$ fragments of mouse anti-collagen adhesin (antiCNA) monoclonal antibody 3B12 was used as the primary antibody (provided by Dr. Joseph Patti; Inhibitex, Inc., Alpharetta, GA). The primary antibody was prepared as a 1:100 dilution from $5.9 \mathrm{mg} / \mathrm{mL}$ stock solution into $3 \mathrm{~mL}$ of PBS. The primary antibody was manually infused slowly through the flow chamber with a $5 \mathrm{~mL}$ syringe and allowed to bind for $60 \mathrm{~min}$. Unbound primary antibodies were washed by infusing PBS (without microparticles) for $10 \mathrm{~min}$. Next, a DyLight 488-conjugated AffiniPure (Fab') 2 fragment goat anti-mouse IgG (493 nm/518 nm excitation/emission; Jackson Immuno Research Laboratories, Inc., West Grove, PA) was used as the secondary antibody and prepared as a 1:100 dilution from a $1 \mathrm{mg} / \mathrm{mL}$ stock solution into $3 \mathrm{~mL}$ of PBS. The secondary antibody was also manually infused and allowed to bind for $30 \mathrm{~min}$. Unbound secondary antibodies were washed by infusing PBS with $0.2 \% \mathrm{w} / \mathrm{v} \mathrm{NaN}_{3}$ for $10 \mathrm{~min}$. The biofilm culture was imaged immediately.

\section{Biofilm Imaging and Determination of Interior Oxygen Partial Pressure}

The biofilm interior was imaged at $20 \times$ magnification with a combined fluorescence $z$-stack and time lapse capture. Stack images were captured at two time points 1 min apart. The zstack step size was $1 \mu \mathrm{m}$ for a total stack height of $\sim 19 \mu \mathrm{m}$, which was the observed biofilm thickness. This process is referred to as a 4D capture, and it enabled three-dimensional reconstruction of the z-stack with higher resolution, as opposed to a conventional 3D capture. Image analysis was performed using NIH Image-J freeware. Mean values of microparticle and biofilm florescence intensity across the different biofilm sections were also obtained with line profiles that segmented each image across their width (at 20x magnification, image area was $443.76 \mu \mathrm{m}$ long and $330.24 \mu \mathrm{m}$ wide). Calculated values of the oxygen concentration with respect to position within the biofilm were obtained by applying the two-site Stern-Volmer calibration to the measured values of fluorescence intensity.

\section{Results}

\section{Microparticle Synthesis, Size Distribution, and SEM Imaging}

Figure 1 shows the fluorescent microparticle size distribution compared to that of the $S$. aureus bacteria. Mean microparticle and bacterium diameter were $1.19 \pm 0.23$ and $0.87 \pm$ $0.01 \mu \mathrm{m}$, respectively. Figure 2a shows a scanning electron micrograph (SEM) of the microparticles, from which the particles are observed to be spherical in shape. Additionally, Figure $2 \mathrm{~b}$ shows a fluorescence image of the microparticles where the red fluorescence marks $\mathrm{Ru}\left(\mathrm{Ph}_{2} \mathrm{phen}_{3}\right) \mathrm{Cl}_{2}$. 


\section{Calibration Results}

Changes in microparticle fluorescence intensity were monitored by fluorescence microscopy. The correlation between fluorescence intensity and dissolved oxygen content was obtained by applying the two-site Stern-Volmer model (Eq. 2) to fit microparticle fluorescence intensity data for the partial pressure range of $0-160 \mathrm{~mm} \mathrm{Hg}(0-100 \%$ oxygen saturation). Figure 3 shows the calibration results for the microparticles. Regression results were $0.030\left(\mathrm{~mm} \mathrm{Hg}^{-1}\right.$ for the Stern-Volmer quenching constant $\left(K_{\mathrm{SV}}\right)$ and 0.994 for the coefficient of determination $\left(R^{2}\right)$. Additionally, the calculated value of the quenched fluorophore fraction $\left(f_{1}\right)$ was $0.95 \pm 0.02$.

\section{S. aureus Biofilm Culture and Imaging}

A method was established to culture $S$. aureus biofilms on collagen-coated cover slips containing the fluorescent oxygen-sensing microparticles. Additional steps were taken to ensure the microparticles would be within the biofilm volume by washing with a suspension of the microparticles in PBS before and after the 6-h culture period. Due to significant biofilm-to-biofilm variation in structure and cellular density, herein we present results from a single live biofilm culture in order to demonstrate the utility of the oxygen-sensing microparticles. On-going studies focus on rigorously defining the dynamics of oxygen profiles, $S$. aureus biology and biofilm structure in replicate samples. Figure 4a shows a three-dimensional reconstruction of the $S$. aureus biofilm from one of four randomly selected sections of the biofilm under dynamic lighting. Figure $4 \mathrm{~b}$ shows a threedimensional reconstruction of the chosen section under maximum intensity projection (MIP), where the fluorescent microparticles are observed dispersed through the volume of the $S$. aureus biofilm. Additionally, Figure 4c shows the MIP image of the chosen section with the biofilm fluorescence opacity set to $0 \%$. In this image, the microparticles are observed within the biofilm. Figure $4 \mathrm{~b}$ and $\mathrm{c}$ demonstrate that the established methodology has allowed for the culture of the $S$. aureus biofilm with the fluorescent microparticles dispersed through its volume. The other three randomly selected locations showed similar results.

The established methodology also permitted the preliminary study of oxygen concentration through the volume of the biofilm and its comparison to the biofilm structure. Figure 5a shows the calculated oxygen concentration (in partial pressure) relative to position within the biofilm. Oxygen concentration was calculated by employing Equation (3) together with the calculated values of $K_{\mathrm{SV}}$ and $f_{1}$ and the normalized fluorescence intensity, which accounts for fluorescence attenuation through the biofilm. The results shown in Figure 5a correspond to four randomly selected sections of the biofilm (each $443.76 \mu \mathrm{m}$ long and $330.24 \mu \mathrm{m}$ wide area at $20 \times$ magnification). From Figure $5 \mathrm{a}$ we observe that the oxygen concentrations in the considered sections of the biofilm decreased by $\sim 50 \%$ from the top surface $(z=19 \mu \mathrm{m})$ to the bottom $(z=0 \mu \mathrm{m})$. From Figure $5 \mathrm{~b}$, we can observe that fluorescence intensity of the biofilm with film depth shows the opposite trend: $S$. aureus fluorescence intensity increased with biofilm depth, implying a greater cell density toward the bottom of the biofilm. Figure $5 \mathrm{~b}$ also provides some evidence to the irregular structure of the biofilm, as the magnitude of oxygen concentration range varies with $x-y$ location. Lastly, Figure 6 shows a direct comparison between oxygen concentration and biofilm structure for all locations and depicts the inverse relationship between biofilm fluorescence intensity, a measure of cell density, and oxygen concentration.

\section{Discussion}

We describe the synthesis and characterization of fluorescent oxygen-sensing microparticles for the measurement of oxygen concentration through the volume of bacterial biofilms. The 
protocol is based on the Stöber synthesis of silica microparticles, to which the fluorophores $\mathrm{Ru}\left(\mathrm{Ph}_{2} \mathrm{phen}_{3}\right) \mathrm{Cl}_{2}$ and Nile blue chloride were immobilized onto the surface of the synthesized microparticles. The immobilization process used for the dye-coated microparticles was adapted from John et al. (2003), who immobilized $\mathrm{Ru}\left(\mathrm{Ph}_{2} \mathrm{phen}_{3}\right) \mathrm{Cl}_{2}$ and the reference fluorophore safranin onto silica gel. In contrast, we selected Nile blue chloride as our reference fluorophore due to the fact that safranin's emission spectrum overlaps with that of $\mathrm{Ru}\left(\mathrm{Ph}_{2} \mathrm{phen}_{3}\right) \mathrm{Cl}_{2}$. The differing emission spectra between the $\mathrm{Ru}\left(\mathrm{Ph}_{2} \mathrm{phen}_{3}\right) \mathrm{Cl}_{2}$ and the Nile blue chloride allowed us to independently measure their fluorescence via microscopy. $\mathrm{Ru}\left(\mathrm{Ph}_{2} \mathrm{phen}_{3}\right) \mathrm{Cl}_{2}$ was chosen because of its high quantum yield, high oxygen quenching, and thermal stability at $37^{\circ} \mathrm{C}$ (Bacon and Demas, 1987; Kneas et al., 1997). We note that the absorption spectrum of the Nile blue overlaps with the emission spectrum of $\mathrm{Ru}\left(\mathrm{Ph}_{2} \mathrm{phen}_{3}\right) \mathrm{Cl}_{2}$, which could lead to fluorescence resonance energy transfer (FRET) between the two fluorophores. The reported synthesis protocol was optimized to address this issue. We also confirmed the absence of FRET with spectrometry experiments using poly(dimethylsiloxane) (PDMS) films containing the reported particles (data not shown).

We compared the size distribution of the fluorescent microparticles to that of $S$. aureus bacteria. Our design goal was to synthesize particles that were in the same size range as the bacterial cells, yet large enough to prevent potential endocytosis. Additionally, the small size of the microparticles (1) permits more uniform distribution through the substrate, (2) allows for the inclusion of more particles to cover a larger experimental area, and (3) significantly reduces response time by minimizing diffusion limitations of oxygen transport to the fluorophores through the boundary layer of the medium (Klimant et al., 1999; Xu et al., 2001). As shown in Figure 1, the size range of the microparticles is suitable for the desired application, as it is approximately the size of the bacteria. Microparticle mean diameter $(1.19 \pm 0.23 \mu \mathrm{m})$ is $31 \%$ larger than the mean diameter of the $S$. aureus bacteria $(0.87 \pm 0.01$ $\mu \mathrm{m})$. With the Stöber reaction, monodisperse silica particles have been synthesized with high fidelity for size ranges up to $0.8 \mu \mathrm{m}$. However, it has proven difficult to obtain monodisperse particles with larger diameters. Figures $1 \mathrm{a}$ and $2 \mathrm{a}$ demonstrate that the synthesis protocol for the dye-coated microparticles yielded spherical microparticles with a relatively monodisperse size distribution in the $1-\mu \mathrm{m}$ size range.

The calibration of the fluorescent microparticles inside a three-dimensional hydrogel was carried out using the parallel-plate flow chamber mounted on the stage of a fluorescence microscope. This flow chamber system allowed for direct control over dissolved oxygen in the substrate/microparticle environment, as well as measurements of the changes in microparticle fluorescence intensity. The conventional Stern-Volmer model, which pertains to the fluorophores in solution, predicts a linear response of the $\mathrm{Ru}\left(\mathrm{Ph}_{2} \mathrm{phen}_{3}\right) \mathrm{Cl}_{2}$ fluorophore to oxygen. Systems that deviate from this model generally exhibit a downward curvature, mimicking a second order response and suggesting heterogeneities in the carrier structure or a non-uniform distribution of fluorophore molecules throughout the carrier matrix (Bacon and Demas, 1987; Carraway et al., 1991; Xu et al., 1994). The two-site Stern-Volmer model presents a closer description of systems that deviate from the conventional model.

Figure 3 demonstrates that the two-site model is an appropriate model for the calibration of the presented microparticles, as the calibration is close to linearity with a coefficient of determination close to unity $\left(R_{2}=0.994\right)$. In addition, from the two-site model, we calculated the fraction of quenched fluorophore $\left(f_{1}\right)$. This parameter is a measure of the oxygen accessibility to $\mathrm{Ru}\left(\mathrm{Ph}_{2} \mathrm{phen}_{3}\right) \mathrm{Cl}_{2}$ molecules. Results from the calibration using the two-site Stern-Volmer model reveal that $f_{1}=0.95 \pm 0.02$. In other words, $95 \%$ of the available $\mathrm{Ru}\left(\mathrm{Ph}_{2} \mathrm{phen}_{3}\right) \mathrm{Cl}_{2}$ molecules were accessible for oxygen molecules to quench. This 
result is comparable to the results obtained by Carraway et al. (1991) for the $\mathrm{Ru}\left(\mathrm{Ph}_{2} \mathrm{phen}_{3}\right) \mathrm{Cl}_{2}$ fluorophore immobilized on silica carriers.

We have also developed a methodology for the quantitative characterization of oxygen profiles within a complex biofilm structure. From Figure $4 a$ and $b$ we can observe the bacterial cells organized in non-uniform vertical structures. These structures have been observed previously in studies with Staphylococcal and Pseudonomal strains (Salek et al., 2009; Williams and Bloebaum, 2010), and provide evidence of biofilm formation.

Furthermore, Figure $4 \mathrm{~b}$ supports this methodology as suitable for studying oxygen transport through bacterial biofilms, as the microparticles are observed to be distributed through the volume of the biofilm. Prior to image capture, the system within the flow chamber was allowed to reach steady state. Thus, the observed gradients in oxygen concentration with biofilm depth are due to consumption from the biofilm, rather than to bulk diffusion. The oxygen profiles within the biofilm are highly variable and depend on the specific location within the biofilm (Fig. 5), and presumably, heterogeneity in biofilm structure. Figure 6 further illustrates the inverse relationship between oxygen concentration and biofilm fluorescence, suggesting a connection between local levels of oxygen consumption and variable bacterial cell density within the biofilm structure.

We conclude that the oxygen-sensing microparticles are suitable for studies of oxygen transport through the volume of live biofilms. This work also lays the foundation for future detailed studies correlating $S$. aureus biofilm structure to relevant biological parameters that govern biofilm development in physiological conditions and secondary infection.

\section{Acknowledgments}

We thank Andrew Vache in the UMBC Department of Physics for his technical assistance with the SEM and Dr. Brian Cullum in the UMBC Department of Chemistry and Biochemistry for valuable technical advice. This work was funded by the Henry Luce Foundation, UMBC, and NIH-NINDS (R01NS065205).

\section{References}

Acosta M, Ymele-Leki P, Kostov Y, Leach J. Fluorescent microparticles for sensing cell microenvironment oxygen levels within 3D scaffolds. Biomaterials. 2009; 30(17):3068-3074. [PubMed: 19285719]

Bacon JR, Demas JN. Determination of oxygen concentrations by luminescence quenching of a polymer-immobilized transition metal complex. Anal Chem. 1987; 59:2780-2785.

Brasuel M, Kopelman R, Aylott JW, Clark H, Xu H, Hoyer M, Miller TJ, Tjalkens R, Philbert MA. Production, characteristics, and applications of fluorescent PEBBLE nanosensors: Potassium, oxygen, calcium, and pH imaging inside live cells. Sensors Mater. 2002; 14(6):309-338.

Busscher H, van der Mei H. Microbial adhesion in flow displacement systems. Clin Microbiol Rev. 2006; 19(1):127-141. [PubMed: 16418527]

Carraway ER, DeGraff BA, Bacon JR, Demas JN. Photophysics and photochemistry of oxygen sensors based on luminescent transitionmetal complexes. Anal Chem. 1991; 63:337-342.

Chu V, Crosslin D, Friedman J, Reed S, Cabell C, Griffiths R, Masselink L, Kaye K, Corey G, Reller L, Stryjewski M, Schulman K, Fowler VJ. Staphylococcus aureus bacteremia in patients with prosthetic devices: Costs and outcomes. Am J Med. 2005; 118(12):1416. [PubMed: 16378797]

Cramton S, Ulrich M, Götz F, Döring G. Anaerobic conditions induce expression of polysaccharide intercellular adhesin in Staphylococcus aureus and Staphylococcus epidermidis. Infect Immun. 2001; 69(6):4079-4085. [PubMed: 11349079]

Folkesson A, Haagensen J, Zampaloni C, Sternberg C, Molin S. Biofilm induced tolerance towards antimicrobial peptides. Plos ONE. 2008; 3(4):e1891. [PubMed: 18382672] 
Gao D, Wang Z, Liu B, Ni L, Wu M, Zhang Z. Resonance energy transfer-amplifying fluorescence quenching at the surface of silica nanoparticles toward ultrasensitive detection of TNT. Anal Chem. 2008; 80(22):8545-8553. [PubMed: 18847285]

Ge X, Hanson M, Shen H, Kostov Y, Brorson KA, Frey DD, Moreira AR, Rao G. Validation of an optical sensor-based high-throughput bioreactor system for mammalian cell culture. J Biotechnol. 2006; 122(3):293-306. [PubMed: 16423420]

Goldsmith HL, Turitto VT. Rheological aspects of thrombosis and haemostasis: Basic principles and applications. ICTH-Report-Subcommittee on Rheology of the International Committee on Thrombosis and Haemostasis. 1986; 55(3):415-435.

Gotz F. Staphylococcus and biofilms. Mol Microbiol. 2002; 43(6):1367-1378. [PubMed: 11952892]

John GT, Klimant I, Wittman C, Heinzle E. Integrated optical sensing of dissolved oxygen in microtiter plates: A novel tool for microbial cultivation. Biotechnol Bioeng. 2003; 81(7):829-836. [PubMed: 12557316]

Klimant I, Meyer V, Kuhl M. Fiber-optic oxygen microsensors: A new tool in aquatic biology. Limnol Oceanogr. 1995; 40(6):1159-1165.

Klimant I, Ruckruh F, Liebsch G, Stangelmayer A, Wolfbeis OS. Fast response oxygen micro-optodes based on novel soluble ormosil glasses. Mikrochim Acta. 1999; 131:35-46.

Kneas KA, Xu W, Demas JN, DeGraff BA. Oxygen sensors based on luminescence quenching: Interaction of tris(4,7-diphenyl-1,10-phenanthroline)ruthenium(II) chloride and pyrene with polymer supports. Appl Spectrosc. 1997; 51(9):1346-1351.

Lebedev A, Cheprakov A, Sakadzic S, Boas D, Wilson D, Vinogradov S. Dendritic phosphorescent probes for oxygen imaging in biological systems. ACS Appl Mater Interfaces. 2009; 1(6):12921304. [PubMed: 20072726]

Lesens O, Hansmann Y, Brannigan E, Remy V, Hopkins S, Martinot M, Meyer P, Connel B, Monteil $\mathrm{H}$, Christmann D, Bergin C. Positive surveillance blood culture is a predictive factor for secondary metastatic infection in patients with Staphylococcus aureus bacteraemia. J Infect. 2004; 48(3): 245-252. [PubMed: 15001303]

Mascari L, Ross JM. Hydrodynamic shear and collagen receptor density determine the adhesion capacity of $S$. aureus to collagen. Ann Biomed Eng. 2001; 29(11):956-962. [PubMed: 11791678]

Mohamed N, Teeters MA, Patti JM, Höök M, Ross JM. Inhibition of Staphylococcus aureus adherence to collagen under dynamic conditions. Infect Immun. 1999; 67(2):589-594. [PubMed: 9916063]

Mohamed N, Rainier TR, Ross JM. Novel experimental study of receptor-mediated bacterial adhesion under the influence of fluid shear. Biotechnol Bioeng. 2000; 68(6):628-636. [PubMed: 10799987]

Patti JM, Bremell T, Krajewska-Pietrasik D, Abdelnour A, Tarkowski A, Rydén C, Höök M. The Staphylococcus aureus collagen adhesin is a virulence determinant in experimental septic arthritis. Infect Immun. 1994; 62(1):152-161. [PubMed: 8262622]

Salek MM, Jones SM, Martinuzzi RJ. The influence of flow cell geometry related shear stresses on the distribution, structure and susceptibility of Pseudomonas aeruginosa 01 biofilms. Biofouling. 2009; 25(8):711-725. [PubMed: 20183130]

Stewart P, Costerton J. Antibiotic resistance of bacteria in biofilms. Lancet. 2001; 358(9276):135-138. [PubMed: 11463434]

Stöber W, Fink A, Bohn E. Controlled growth of monodisperse silica spheres in the micron size range. J Colloid Interface Sci. 1968; 26:62-69.

Williams D, Bloebaum R. Observing the biofilm matrix of Staphylococcus epidermidis ATCC 35984 grown using the CDC biofilm reactor. Microsc Microanal. 2010; 16(2):143-152. [PubMed: 20205969]

Wolfbeis OS. Fiber-optic chemical sensors and biosensors. Anal Chem. 2006; 78(12):3859-3874. [PubMed: 16771528]

Xu W, McDonough RC, Langsdorf B, Demas JN, Degraff BA. Oxygen sensors based on luminiscence quenching: Interactions of metal complexes with the polymer supports. Anal Chem. 1994; 66:4133-4141. [PubMed: 7847622]

Xu H, Aylott JW, Kopelman R, Miller TJ, Philbert MA. A real-time ratiometric method for the determination of molecular oxygen inside living cells using sol-gel-based spherical optical 
nanosensors with applications to rat C6 glioma. Anal Chem. 2001; 73(17):4124-4133. [PubMed: 11569801]

Ymele-Leki P, Ross JM. Erosion from Staphylococcus aureus biofilms grown under physiologically relevant fluid shear forces yields bacterial cells with reduced avidity to collagen. Appl Environ Microbiol. 2007; 73(6):1834-1841. [PubMed: 17277217] 

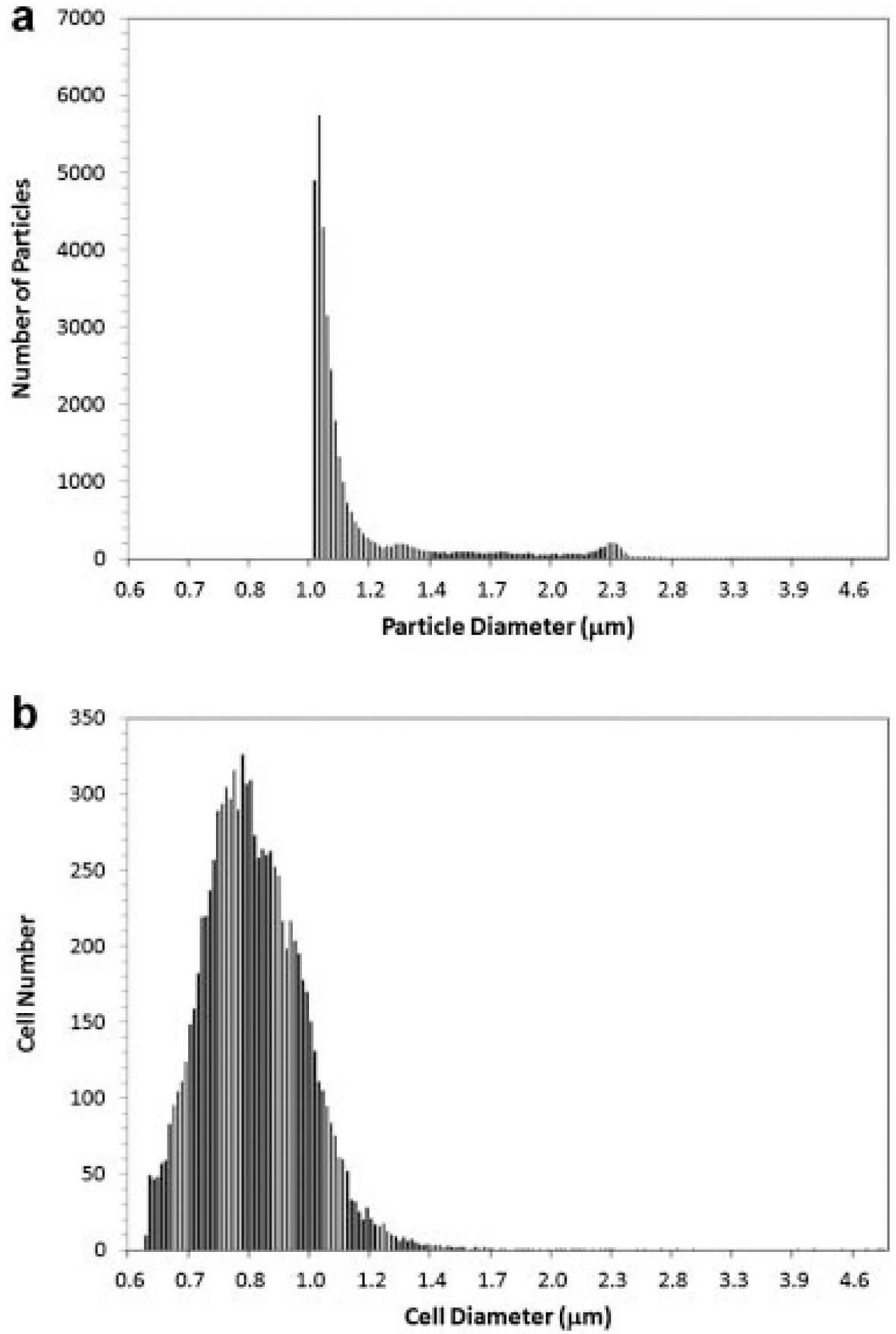

Figure 1.

Size distributions of the fluorescent oxygen-sensing microparticles (a) and $S$. aureus bacteria (b) as measured by a Coulter Counter. Measured mean diameters were $1.19 \pm 0.23$ and 0.87 $\pm 0.01 \mu \mathrm{m}$ for the microparticles and the bacterial cells, respectively. 

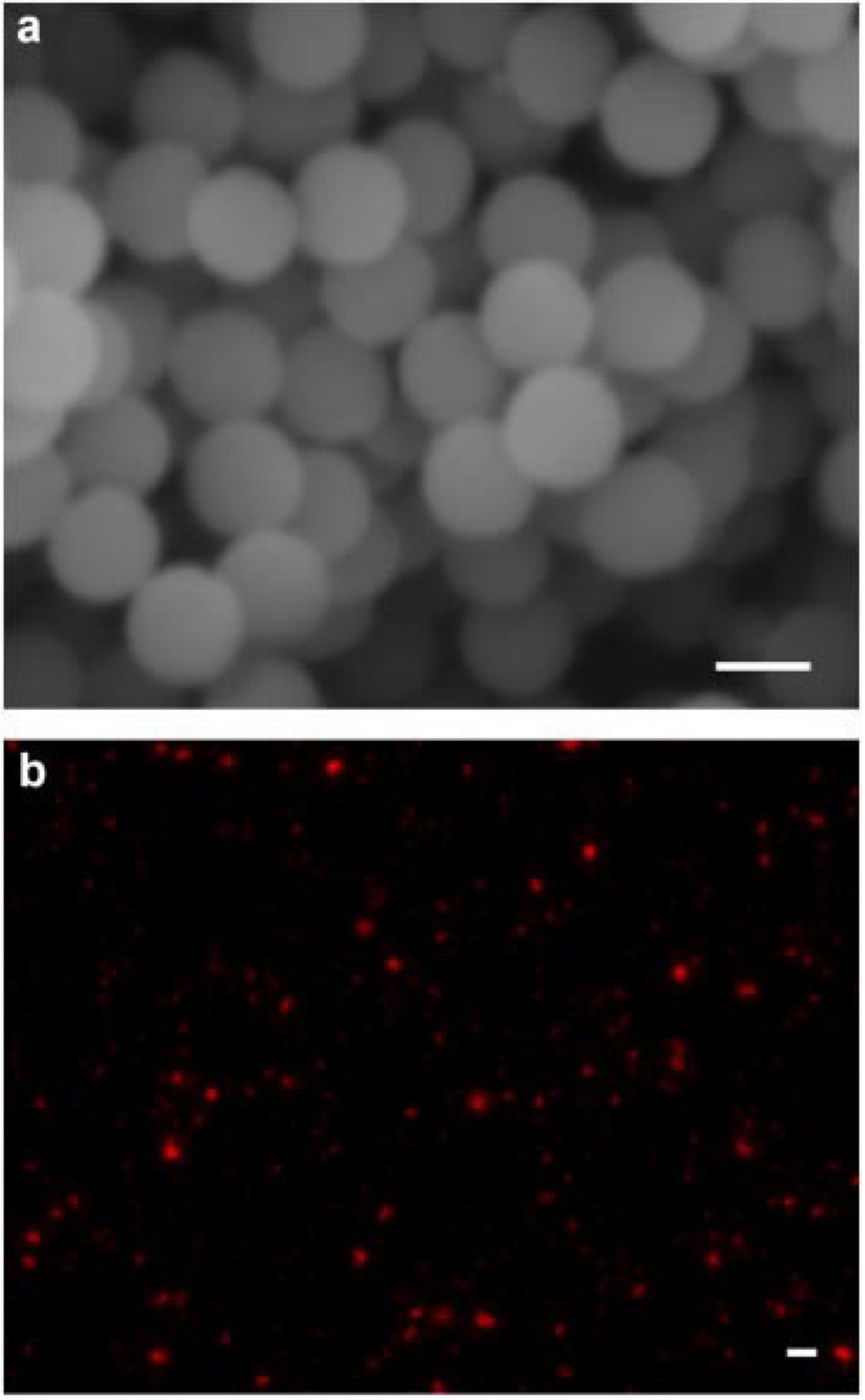

Figure 2.

a: SEM of the fluorescent oxygen-sensing microparticles. Magnification $=12,000 \times$. Scale bar $=1 \mu \mathrm{m}$. b: Fluorescence image of the microparticles. Red fluorescence marks the oxygen-sensitive fluorophore $\mathrm{Ru}\left(\mathrm{Ph}_{2} \mathrm{phen}_{3}\right) \mathrm{Cl}_{2}$. Magnification $=20 \times$. Scale bar $=10 \mu \mathrm{m}$. 


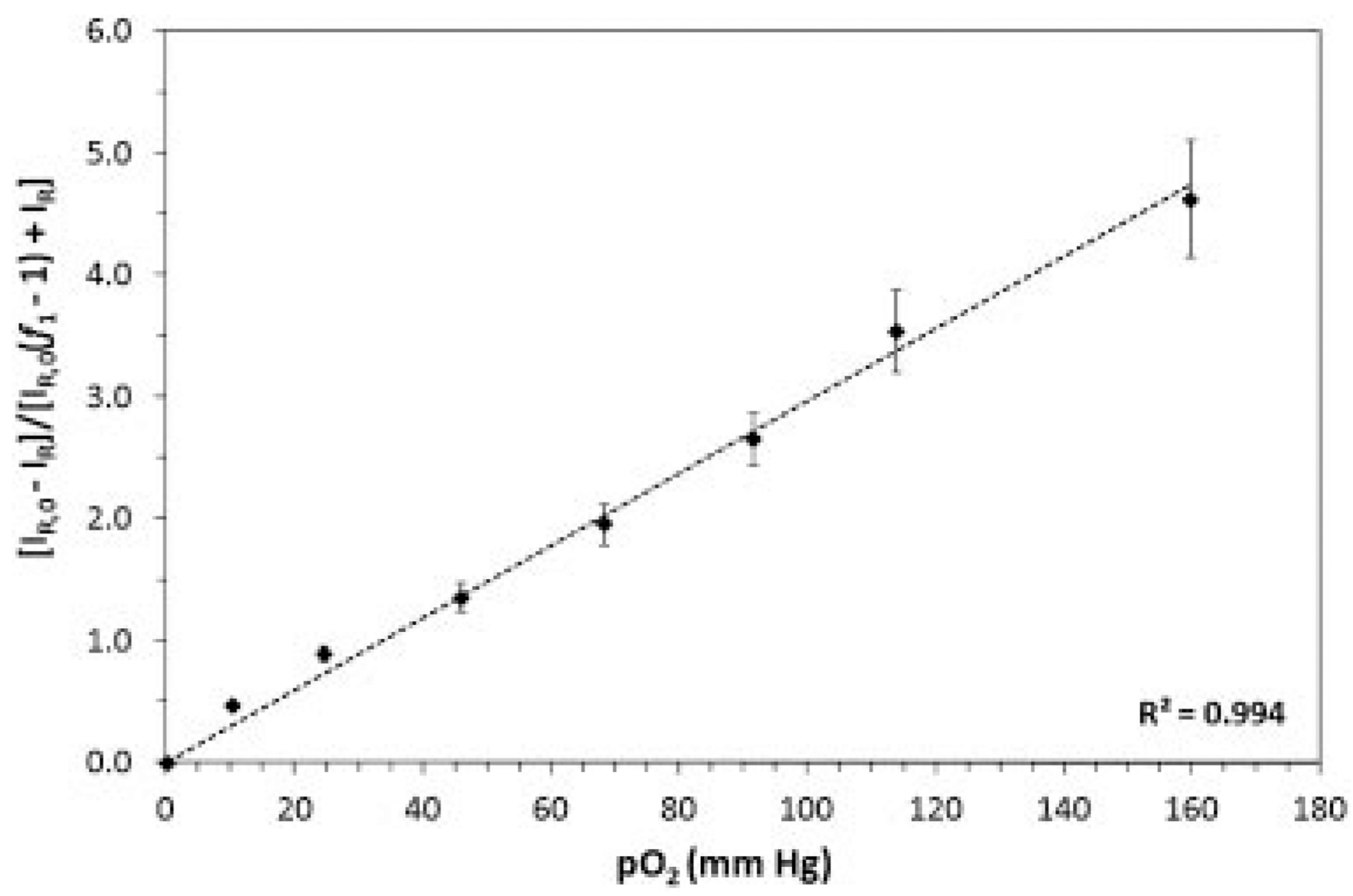

Figure 3.

Calibration of the fluorescent oxygen-sensitive microparticles using the two-site SternVolmer model. Regression values obtained were $0.030\left(\mathrm{~mm} \mathrm{Hg}^{-1}\right.$ for the Stern-Volmer quenching constant $\left(K_{\mathrm{SV}}\right)$ and 0.994 for the coefficient of determination $\left(R^{2}\right)$. Data shown as mean \pm standard error for three trials. 
a

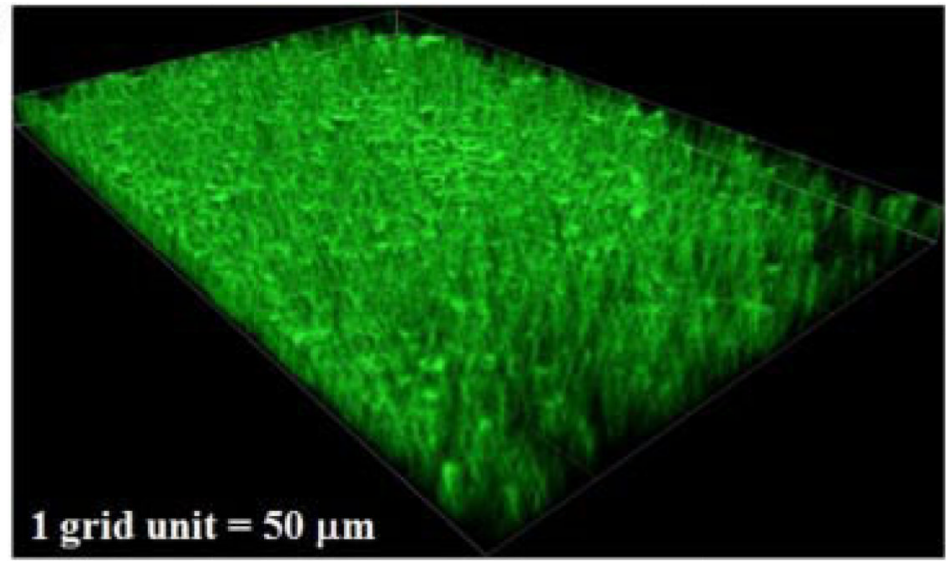

b

1 grid unit $=50 \mu \mathrm{m}$

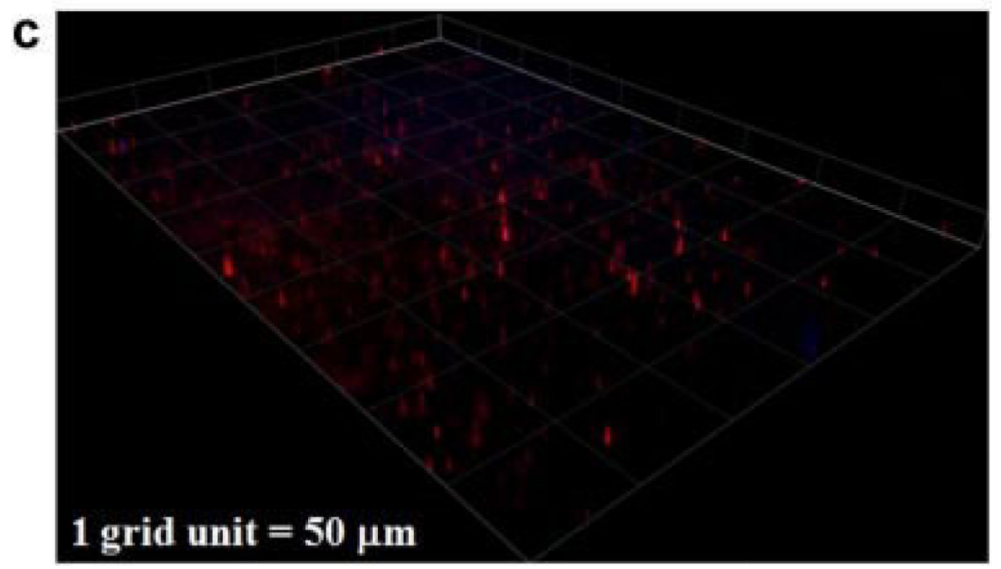

Figure 4.

Three-dimensional reconstruction of z-dimension captures for one of the four randomly selected $443.76 \mu \mathrm{m} \times 330.24 \mu \mathrm{m}$ sections of the $S$. aureus biofilm cultured on top of collagen-coated cover slip containing $1 \mathrm{mg} / \mathrm{mL}$ of the oxygen-sensing microparticles. Images were acquired at $20 \times$ magnification. a: Three-dimensional reconstruction of the chosen location shown under dynamic lighting. Opacity of the fluorescence from the oxygen-sensing microparticles was set to $0 \%$ in order to display the fluorescence from the biofilm only. b: Maximum image projection (MIP) image of the chosen location, where the oxygen-sensing microparticles can be observed within the $S$. aureus biofilm. c: MIP image 
of chosen location, with biofilm fluorescence opacity at $0 \%$ to observe the oxygen-sensing microparticles. Red fluorescence marks the $\mathrm{Ru}\left(\mathrm{Ph}_{2} \mathrm{phen}_{3}\right) \mathrm{Cl}_{2}$ fluorophore and the bluepseudo color marks Nile blue chloride fluorescence. 

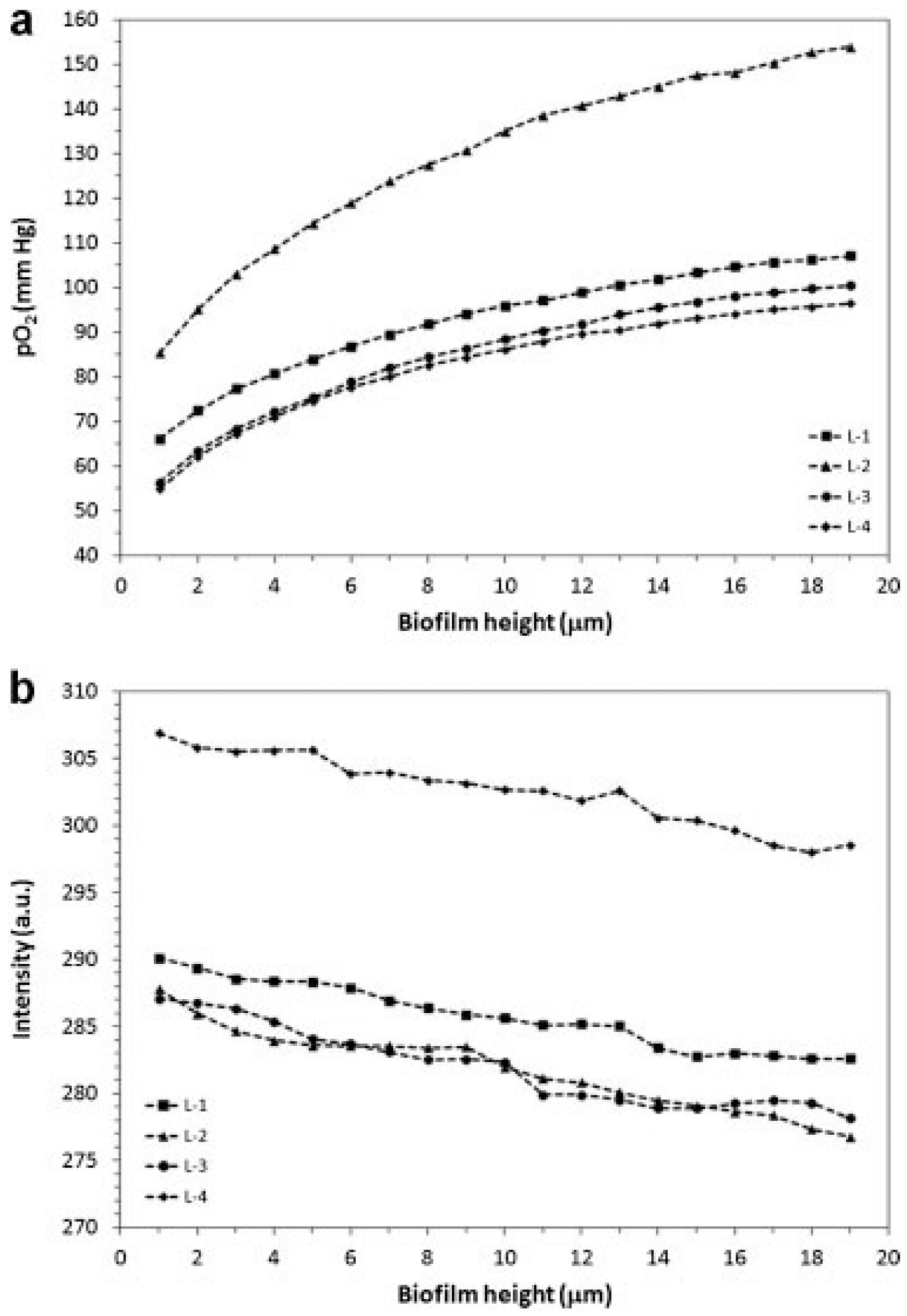

Figure 5.

a: Measured change in oxygen concentration with biofilm height (from $z=0 \mu \mathrm{m}$ at the bottom to $z=19 \mu \mathrm{m}$ at the top surface) for four randomly selected $443.76 \mu \mathrm{m} \times 330.24 \mu \mathrm{m}$ sections of the $S$. aureus biofilm cultured on collagen-coated cover slips containing $1 \mathrm{mg} /$ $\mathrm{mL}$ of the oxygen-sensing microparticles. b: Measured change in biofilm fluorescence intensity with height for the four randomly selected locations. 

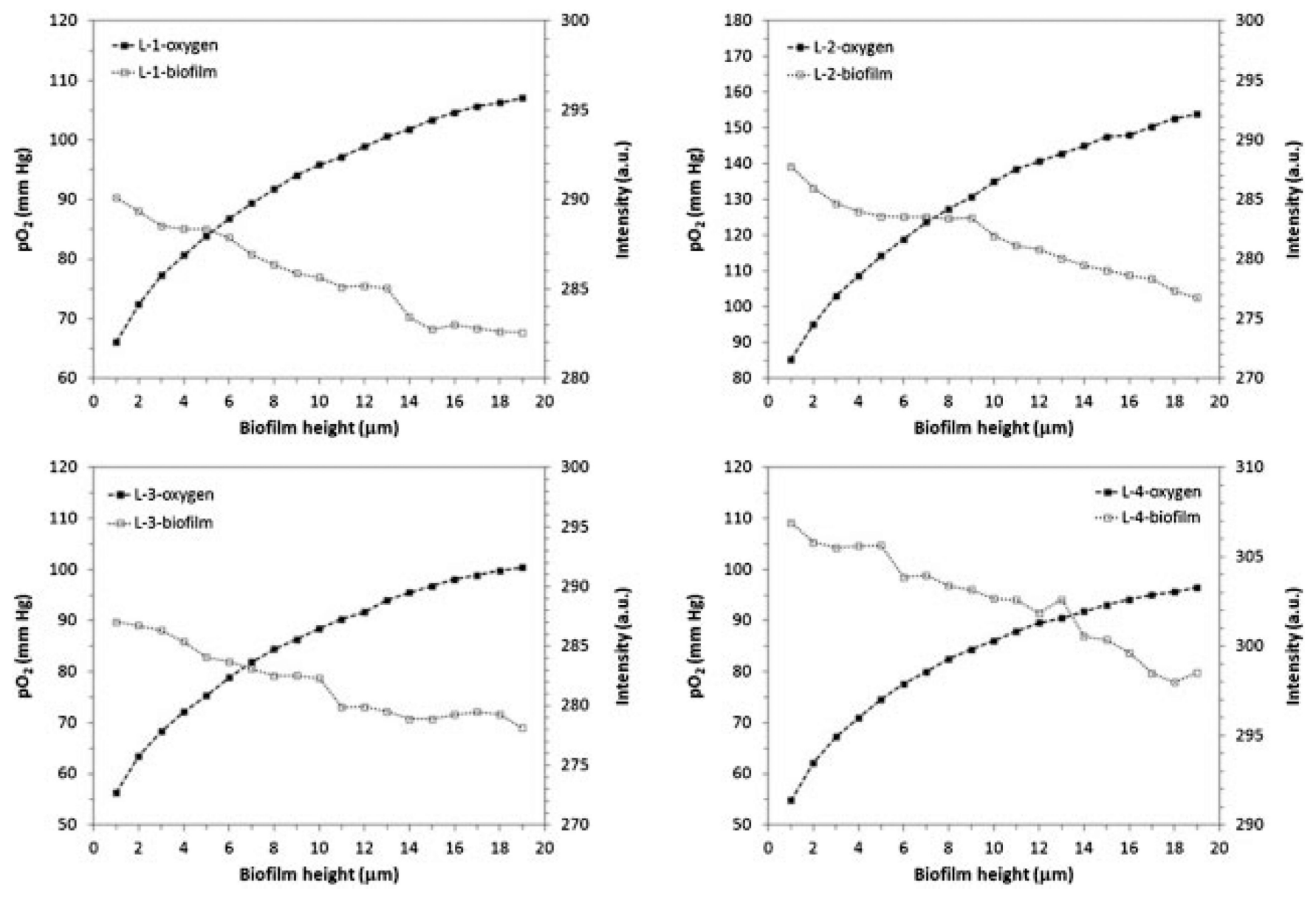

Figure 6.

Comparison between oxygen concentration and biofilm fluorescence for all locations. Left axis displays biofilm fluorescence intensity and right axis displays oxygen concentration measured in $(\mathrm{mm} \mathrm{Hg})^{-1}$ of partial pressure. The $x$-axis represents biofilm height from $z=0$ $\mu \mathrm{m}$ at the bottom of the biofilm to $z=19 \mu \mathrm{m}$ at the top surface. 